Tesis. Año 12, 11(13), 2018, 105-128

\title{
El Conspirador y Hlanca sol, el ideal de hombre/mujer en la novelística de Mercedes Cabello de Carbonera
}

\author{
Norma Isabel Barúa Lanchippa \\ norma.barua@yahoo.com.pe
}

\section{Resumen}

Este artículo propone un análisis epistemológico de la propuesta ideológica de Mercedes Cabello de Carbonera sobre el binomio social hombre/mujer, plasmada en sus artículos académicos, y desarrollada en su novelística. Nuestro postulado es que la escritora peruana fundamenta su proyecto de sociedad liberal a partir del papel que tanto el hombre como la mujer deben jugar para convertirse en la respuesta a los problemas que el Perú afrontaba a finales del siglo XIX. Para ello planteamos a partir de la Teoría de la Complementariedad que, de acuerdo con el pensamiento ideológico cabelliano y siempre desde su narrativa naturalista, los protagonistas de sus dos últimas novelas, El Conspirador y Blanca Sol, representan la antítesis del binomio ideal de hombre/mujer del Perú de cara al siglo XX.

Palabras clave: Mercedes Cabello; Naturalismo; El Conspirador; Blanca Sol; narrativa peruana del siglo XIX; Teoría de la Complementariedad de los Sexos.

\begin{abstract}
The present article proposes an epistemological analysis of the ideological position Mercedes Cabello de Carbonera offers about the social binomial man/ woman developed in her academic articles and in her narrative production. We postulate that the Peruvian writer supports her liberal society agenda based on the roles men and women must play to become the answer to the problems Peru confronted at the end of the XIX century. To do so, we have applied the Theory of Complementarity of Sexes, taking into account Cabello's ideological thinking and her naturalistic approach, to the protagonists of Cabello's two last novels, El Conspirador and Blanca Sol; both figures represent the ideal couple towards Peru in the XX century.
\end{abstract}

Keywords: Mercedes Cabello; Naturalism; El Conspirador; Blanca Sol; XIX century Peruvian narrative; Theory of Complementarity of the Sexes. 


\section{El Conspirador y Hlanea Sol, el ideal de hombre/mujer en la novelística de Mercedes Cabello de Carbonera}

\section{Introducción}

La propuesta ideológica de Mercedes Cabello de Carbonera sobre los modelos de hombre y mujer, postulada a lo largo de sus artículos de reflexión y desarrollada en su novelística, ofrece una perspectiva original y de gran actualidad. Doña Mercedes fundamentó su proyecto de sociedad liberal a partir del papel que tanto hombres como mujeres debían jugar para convertirse en respuesta a los problemas que el Perú afrontaba a finales del siglo XIX. En otras palabras, Cabello de Carbonera suscribía el principio de la responsabilidad personal del ciudadano frente a la sociedad y al país. Así vemos que, de acuerdo con el planteamiento cabelliano, siempre desde su narrativa naturalista, la figura de Jorge Bello, el personaje principal de la novela El Conspirador, junto con la figura de Blanca Sol, protagonista de la novela del mismo nombre, representan la antítesis del binomio hombre/mujer del Perú de cara al siglo XX.

En primer lugar, planteamos que en su obra la autora denuncia el perjuicio nacional que tanto hombres como mujeres indiferentes a la causa nacional ocasionan cuando se desprecia el orden moral y ético en la construcción de una nación progresista. En efecto, la visión positivista de Mercedes Cabello de Carbonera responde a una tesis de complementariedad social del papel del hombre y la mujer en el estado peruano. Es decir, la responsabilidad del progreso nacional no solo recae en el hombre, es decir al sexo masculino, sino que la mujer también está llamada a trabajar por el desarrollo y el bien del país, desde una posición equitativamente complementaria.

Así, la autora ofrece sus dos últimas obras, Blanca Sol (1888-1889), y El Conspirador (1892), la tipología de tanto hombre como mujer que se construyen como los anti-modelos de ciudadanos liberales. En particular en El Conspirador, Cabello de Carbonera realiza un examen de la personalidad de aquellos hombres que se acercan a la política con agendas personales. Desde su 
perspectiva naturalista-liberal, doña Mercedes propone puntualizar cuáles son los vicios que los hombres en la vida pública adolecen. La novela se construye, entonces, como denuncia del tipo venal de políticos que, lamentablemente, son los que se adueñan del destino del país. Si bien su novela no fue la primera en tratar el tema de la idoneidad de la clase política nacional, esta fue el intento más extenso y serio de la cuestión dentro de la novelística peruana de finales del diecinueve.

Es pertinente indicar que ambas obras se escriben pocos años después de la desastrosa Guerra del Pacífico. Doña Mercedes, testigo presencial de uno de los más desastrosos acontecimientos históricos del país, vio de primera mano las secuelas económicas, sociales y políticas en que quedó sumido el Perú a finales del siglo XIX. Fiel a su impronta positivista, la autora moqueguana hizo hincapié sobre el papel de la literatura como una herramienta de ingeniería social para promover la conciencia cívica y el avance del Perú como nación progresista, sobre todo en las élites sociales llamadas a conducir el país; su énfasis fue especialmente riguroso en cuanto a la educación de la mujer, a la que le exige una participación mucho más activa en la reconstrucción del país.

La intención explícita de doña Mercedes Cabello de Carbonera era establecer nuevos paradigmas sociales tanto para los hombres como las mujeres desarrollados en los personajes de sus novelas Blanca Sol y El Conspirador. Los dos protagonistas, Jorge Bello, de ElConspirador, y Blanca Sol, de la novela del mismo nombre, cada uno desde sus respectivas posiciones, ofrecen el reverso de lo que debía ser el papel del binomio varón/mujer, dentro del gran esquema social cabelliano. En tal sentido, es de notar los principios morales postulados por la escritora moqueguana en su carta pública "La Religión de la Humanidad" escrita en 1892 a Enrique Lagaguirre. Esta obra, que dicho sea de paso fue muy controversial en su tiempo, desarrolló su posición sobre las mujeres, el trabajo remunerado y la familia, a la vez que hizo clara la misión de la literatura como agente de cambio social.

Entre los escritores peruanos finiseculares, Mercedes Cabello de Carbonera es la primera que se atreve a experimentar con la entonces nueva corriente naturalista que le permite abordar temas polémicos tales como, por ejemplo, los derechos cívicos y responsabilidades de la mujer ante la sociedad. Así vemos que partir de su obra Blanca Sol, Cabello de Carbonera presenta una postura discursiva de denuncia más audaz, postura que se afianza con su siguiente novela El Conspirador. Con esta obra, Cabello de Carbonera se aleja aún más de los modelos románticos de la narrativa nacional, y su discurso se vuelve más ideológico, más provocador ${ }^{1}$ 


\section{Teoría de la Complementariedad de los Sexos}

Para efectos del estudio de las figuras femeninas y masculinas en las dos novelas cabellianas hemos basado el análisis a partir de una visión de complementariedad de los sexos con el propósito de explicar tanto el papel de la mujer como la del hombre de cara a la sociedad y frente a los problemas nacionales. Entendemos la complementariedad, desde la fundamentación teórico-filosófica formulada por Niels Bohr, como la relación entre dos o más elementos, aparentemente paradójicos, en los que existe una relación de exclusión, pero que son necesarios para una comprensión integral del fenómeno que se analiza ${ }^{2}$. En tal sentido, la complementariedad se aplica al concepto de mujer como la persona bumana femenina, cuyo estatuto ontológico incluye la radicalidad del sexo femenino como parte fundamental de su ser. A partir de esta concepción, postulamos que tanto Mercedes Cabello como las escritoras del XIX comprendieron la participación de las mujeres en la historia nacional en igualdad de condiciones en el devenir social, aunque no en igualdad de circunstancias. Es decir, las mujeres estaban destinadas a colaborar como miembros útiles de la sociedad, como individuos pensantes, con derechos y responsabilidades, con diversidad y no desigualdad.

En segundo lugar, y siguiendo la línea de investigación arriba mencionada, El Conspirador se estructura dentro de la visión cabelliana del binomio social hombre/mujer, y no como una fotografía de la situación política del país o el retrato de algunos de los caudillos del contexto histórico que le tocó vivir. En efecto, desde sus primeros trabajos de crítica literaria, Mercedes Cabello se embarca en una tarea de ingeniería social iniciada con la publicación de sus artículos de opinión sobre la literatura y la sociedad, y desarrollada en sus dos últimas novelas ${ }^{3}$. Así vemos que en Blanca Sol se establece el modelo pernicioso de la mujer vanidosa, ignorante y manipulativa, mientras que en El Conspirador la autora se esfuerza por llamar la atención de los hombres peruanos, especialmente la de los de la clase política, para hacerles comprender las consecuencias que los actos inmorales traen, tanto en el ámbito público como en el privado.

Dicho lo anterior, sostenemos que la obra de Mercedes Cabello de Carbonera se debe enfocar desde la perspectiva de sus dos últimas novelas: es decir, Blanca Sol es la denuncia, desde su credo positivista, de los errores en que la mujer cae por falta de educación, laboriosidad y honradez, especialmente la mujer limeña de la alta burguesía. Por su parte, El Conspirador reprocha el resquebrajamiento de los valores morales del ciudadano peruano, en particular los de la clase política a los que censura por carecer de los valores indispensables para la construcción de un país próspero y progresivo. Por tanto, si se analizan los personajes masculinos y femeninos de Blanca Sol y de El Conspirador, particularmente los de Jorge Bello y Blanca Sol, veremos emerger la complementariedad de los arquetipos femenino y masculino ideales; es decir, la pareja modelo 
llamada a construir la nueva república peruana según los principios positivistas comtianos y sostenidos por doña Mercedes Cabello de Carbonera.

\section{Teoría de la Complementariedad}

Como lo hemos dicho en líneas anteriores, nuestro análisis se sostiene sobre el concepto de complementariedad que se deriva de la tesis epistemológica sobre la teoría cuántica, desarrollada por Niels Bohr. En su artículo "La filosofía de complementariedad y la descripción objetiva de la naturaleza", la Dra. Ana María Rioja, filósofa de la Universidad Complutense de Madrid, argumenta que la postura del físico danés rebasó la problemática epistemológica en el campo de la física para entrar en las grandes cuestiones subyacentes en la búsqueda del conocimiento humano, puesto que el ideal clásico de descripción ha sido subvertido. De acuerdo con Rioja, la teoría de complementariedad de Bohr se establece a partir de «...la combinación de dos o más elementos entre los que se da relación de exclusión, bien en sentido lógico, bien en sentido empírico» ${ }^{4}$. A continuación añade, «la complementariedad de la que aquí se trata, y en ello estriba su novedad, es la que se da entre elementos excluyentes o incompatibles» ${ }^{5}$. En este punto, siempre según Rioja, la teoría de Bohr se aleja de la lógica aristotélica para la demostración de los fenómenos físicos en la medida que incorpora lo lógicamente compatible e incompatible para definir la totalidad. ${ }^{6}$

No obstante, la Dra. Rioja señala con acierto que esta posición no determina una solución simplista «meramente nominal», sino que señala que «la filosofía de la complementariedad pretende ser un marco para la descripción y comprensión de fenómenos aparentemente paradójicos» ${ }^{7}$. Bohr, al decir de Rioja, desde el momento en que cuestiona los conceptos clásicos de la física a través del postulado cuántico, abre el debate epistemológico de no sólo la física, sino del conocimiento científico en general ${ }^{8}$. A ello, nosotros añadiríamos que no sólo lo cuestiona en el ámbito científico, sino que su planteamiento nos debe llevar a la reflexión epistemológica sistematizada del conocimiento humano en general.

Sobre esta base, el Dr. Oscar Navarro Rojas, en su trabajo "El surgimiento de la complementariedad: Niels Bohr y la conferencia de Como", añade que la teoría de la complementariedad es

«...la ampliación necesaria del marco clásico para la comprensión armoniosa de fenómenos aparentemente contradictorios... Así, el marco conceptual de la complementariedad implica, de acuerdo a [sic] Bohr, una contribución a la clarificación filosófica de los supuestos subyacentes tanto al conocimiento humano en general como al científico».9 
En suma, tanto Rioja como Navarro Rojas nos permiten incorporar esta novedosa teoría epistemológica a los demás estudios humanísticos. En nuestro caso, esta teoría nos permitirá analizar productivamente cuál es la visión pionera que Mercedes Cabello desarrolló en sus ensayos sobre mujer, sociedad y literatura, tal como están plasmada en sus dos últimas obras.

En tal sentido, otro de los pensadores que expanden la teoría de la complementariedad en los estudios filosóficos es Wolfgang Strobl, quien postula en su artículo "El Principio de Complementariedad y su significación científico-filosófica" que:

«Una antitética o dialéctica real es imposible, porque las antinomias y contradicciones sobrevienen al mundo tan sólo por los hombres y sus modos de ver». ${ }^{10}$

Es decir, a partir de la reflexión humana, en muchas instancias parcelada desde la revolución epistemológica iniciada en la Ilustración, sobre su entorno físico - en el que se desarrolla tanto en el ámbito material como en el ámbito metafísico- es que se originan los contrasentidos que confunden. Para resolver los enigmas, por tanto, se debe apelar a un plano superior de reflexión trascendiendo las aparentes exclusiones y encontrando cuáles son los puntos de convergencia.

Por tal motivo, siempre siguiendo a Strobl, el principio de complementariedad de Bohr permite llegar a ese plano superior de entendimiento. Al efecto, Strobl sostiene que:

«Para hacer sentir ya ahora la trascendencia filosófica del principio de complementariedad, quisiera citar la forma que le ha dado la espiritualidad francesa con una frase que se adscribe a Lacordaire: "No busques convencer a tu adversario de que yerra, sino busca encontrarte con él en una verdad superior." ${ }^{11}$

Strobl, tomando la frase supuestamente formulada por Henri-Dominique Lacordaire, ilustre dominico francés del siglo XIX, propone acoger las divergencias como los puntos de partida de una nueva forma de ponderar el mundo. En otras palabras, a partir de la teoría de la complementariedad planteada por Niels Bohr, Strobl la concibe como un principio universal «...capaz de crear un nuevo estilo de pensar, más profundo, flexible y conciliador ${ }^{12}$. Desde nuestra perspectiva, consideramos que esta posición se proyecta mucho más productiva para nuestro análisis que las posiciones antitéticas y excluyentes, como en las que se basan la mayoría de los postulados marxistas-feministas, aplicados hasta hoy en los trabajos de crítica literaria de la producción femenina decimonónica. 
Esa misma postura la podemos corroborar en el discurrir filosófico del siglo XXI. En efecto, en este siglo se conciben propuestas como las de Yolanda Cárdenas Gómez, quien la presenta como parte de su tesis doctoral Epistemologia, Ontologia y Complementariedad en Niels Bohr, publicada por la Universidad Complutense de Madrid en 2004. La Dra. Cárdenas Gómez desarrolla su planteamiento como un «...pronunciamiento ontológico que rebase los límites de una concepción instrumentalista, fenomenista o idealista de la mecánica cuántica». ${ }^{13}$ Cárdenas Rojas se basa en los postulados presentados a principios del siglo XX por el físico Niels Bohr, aunque su trabajo busca expandir los campos de exploración científica más allá de lo avanzado hasta ese momento.

Sin embargo, al igual que con lo planteado por Ana Rioja, la postura filosófica de la física cuántica, según Cárdenas Gómez, nos lleva a reflexionar sobre los postulados científicos del saber humano:

«Toda teoría física se da dentro de un marco conceptual, el cual está regido por determinados postulados. Esta tesis se encarga de recordar que los conceptos clásicos fueron construidos dentro del campo de experiencia de esta física y que, por tanto, ellos llevan imbricadas las condiciones del marco clásico, las cuales regulan el uso y el significado de tales conceptos. Esta consideración está directamente relacionada con la postura que mantuvo Bohr frente a la Naturaleza y a nuestro conocimiento de ella: el hombre está en el mundo como actor y espectador, de modo que la realidad posee una legalidad externa, que se nos impone, pero vinculada a la actividad humana a la hora de indagar en ella. Así, el mundo que podemos conocer va cambiando a medida que avanzamos en nuestras investigaciones y descubrimientos, pues la función de las ciencias ya no es estudiar una realidad sustancial, sino buscar las relaciones entre los hechos de nuestras diversas experiencias.» ${ }^{14}$

Es relevante rubricar lo que Cárdenas Gómez argumenta sobre la posición de Bohr frente a la naturaleza: lo que el mundo natural nos presenta ya está dado y lo que cambia en realidad es nuestro conocimiento cada vez más profundo de él. Junto con esa exploración de nuestro entorno, también debemos buscar la relación existente entre las experiencias de las diversas ciencias para una mayor comprensión del mundo que nos rodea. Si esta es la manera en que debemos buscar las respuestas en el ámbito material, con mayor razón se deben aplicar en el ámbito metafísico, donde encontrar la verdad es mucho más valioso pues nos lleva a la comprensión profunda de la naturaleza humana. Por tanto, Bohr enfatiza la revisión de los postulados científicos desde una perspectiva revolucionaria, no solo de la física, sino de todo el saber humano, tal como lo interpreta Cárdenas Gómez:

«Bajo esta fórmula, la complementariedad se convierte en una filosofía de la ciencia en la que se propone, a través de la lección epistemológica, 
que de ella se desprende, una constante ampliación y revisión de los marcos conceptuales de cualquier disciplina científica, y no sólo física, para avanzar en la evolución del conocimiento humano. Lo cual es posible que jamás nos lleve a una unidad de la ciencia, tal y como Bohr la concibió, pero lo que sí plantea es una nueva propuesta filosófica acerca de cómo se produce y evoluciona el conocimiento que el científico posee de la Naturaleza. $»^{15}$

Aunque la mayoría de los investigadores nombrados se refieren a las ciencias duras, este postulado filosófico propuesto también se puede aplicar tanto a las ciencias sociales como a las ciencias humanísticas por un principio de rigurosidad académica. Si los conocimientos científicos se deben revisar y ampliar debido a los avances en las investigaciones científicas y al conocimiento humano, con mayor razón se deben revisar los principios epistemológicos y ontológicos de todas las ciencias que involucren el progreso del conocimiento humano, en especial el conocimiento de lo que significa la naturaleza humana.

\section{Persona humana: conceptos de varón y mujer}

Un primer paso hacia la comprensión de lo que significa esta naturaleza humana ya se ha dado desde el momento en que se ha aclarado la disyunción sexuada de la persona. A la luz de los conceptos antropológicos, sociológicos, psicológicos, fisiológicos y filosóficos, estudiados y establecidos desde mediados del siglo XX sobre el devenir del hombre y de la mujer como miembros distintos mas no desiguales de una misma especie, se ha comenzado a explorar la tercera vía de convivencia mediante el principio de la complementariedad. El ser humano está llamado ontológicamente a la vida comunitaria: su propia naturaleza no se explica sin la proyección del individuo hacia el otro. Ello significa que tanto hombres como mujeres deben colaborar efectiva y eficazmente para llevar a cabo la tarea de conducir el destino de la humanidad en armonía con el medio ambiente que los rodea.

El dilema de la sociedad posmoderna del siglo XXI estriba en el concepto de persona bumana que actualmente se maneja. Hoy en día está en cuestionamiento el principio ontológico del binomio hombre/mujer. María del Carmen Ibañez, en su artículo "Varón y mujer: dos modos distintos de vivir y completar la visión del mundo", afirma lo siguiente:

«Es curioso como [sic], con el paso del tiempo, se ha ido perdiendo el sentido de nuestra propia naturaleza y la capacidad de apreciar la verdad en su mayor evidencia: la realidad... La sociedad, en un contexto de abundancia informativa y escasez reflexiva, ha llegado a dudar de las verdades más profundas de la existencia humana como es la identidad sexuada y el enriquecimiento que esto trae al mundo.. ${ }^{16}$ 
Es decir, el concepto de persona bumana ha caído en tal ambigüedad ontológica que impide analizar con claridad los postulados universales de hombre/ mujer que se manejaban hasta bien entrada la segunda mitad del siglo XX.

Por esa razón, para comprender, desde una perspectiva más abarcadora, el papel que juegan tanto el hombre como la mujer de acuerdo con el pensamiento positivista de Cabello de Carbonera y desarrollado en su obra, se necesita restituir a su significado primigenio la conceptualización del binomio varón/ mujer. En otras palabras, debemos establecer sin ningún tipo de duda a qué nos referimos cuando hablemos de varón y de mujer. Obviar este paso solo traería confusión, o una mirada muy reducida de los planteamientos cabellianos. En tal sentido, la teoría de la complementariedad, entonces, nos ayudará a re-examinar y cuestionar las bases conceptuales feministas que hasta el presente se han aplicado para los estudios de crítica literaria realizados desde la segunda mitad del siglo XX hasta el presente sobre la literatura decimonónica escrita por mujeres.

En primer lugar, debemos establecer muy claramente a qué nos referimos cuando hablamos del concepto de persona humana. Según lo plantea la filósofa Blanca Castilla, hasta bien entrado el siglo XX, la antropología clásica se centraba en el estudio del hombre desde la "...consideración abstracta de naturaleza humana, tratando siempre del «hombre» en general, sin considerar que [en] la realidad solamente existen varones o mujeres." ${ }^{17}$ A renglón seguido añade: "Un estudio de la naturaleza humana en términos asexuados fundamenta la igualdad esencial que se da entre varón y mujer, pero no dice nada acerca de su distinción. ${ }^{18}$ Desde muy antiguo, sobre todo en las culturas occidentales, se ha considerado que el ser humano, ya sea hombre o mujer, comparten ontológicamente una misma naturaleza. Se suponía que el alma espiritual no compartía los accidentes que la materia presenta.

Asumir la sexualidad como parte integrante del individuo fue una importante contribución de Sigmund Freud, quien hizo hincapié en este aspecto de la naturaleza humana. Sin embargo, el problema de la postulación freudiana, como lo explica Julián Marías, consiste en que sus planteamientos se adoptaron y desarrollaron a partir de la interpretación del psicoanálisis y las corrientes ideológicas de la época, como el Naturalismo finisecular: «El error concomitante fue lo que podríamos llamar la interpretación «sexual» (y no sexuada) del sexo, el tomar la parte por el todo.» ${ }^{19}$ Para Freud, el sexo era la fuerza dominante por sobre los demás aspectos de la persona, postulado que redujo el debate hacia el plano puramente material y marginó todo otro elemento que no se amoldara a la interpretación psicoanalítica. Esta corriente ideológica tuvo gran arraigo, sobre todo entre los pensadores marxistas y materialistas, que buscaban un método alejado de las verdades metafísicas para explicar conceptos básicos sobre lo que es el la naturaleza del hombre ${ }^{20}$ en su significado más amplio. 
En realidad, si bien haber colocado la sexualidad de la persona humana fue un paso hacia la dirección correcta, la corriente freudiana tomó una ruta materialista y reductora, tal como ya lo explicamos. Una de las consecuencias lógicas fue la confrontación entre las dos partes que constituyen la especie humana, sobre todo en las culturas occidentales ubicadas en Norteamérica y Europa. Es imposible negar, como lo indica Simone de Beauvoir en su obra "El segundo sexo", que la historia de Occidente corrobora la dominación masculina en todas las culturas; sin embargo, su denuncia solo se fija en una parte de la historia humana, muy reducida en nuestra opinión. Beauvoir se limita a establecer cómo se dio la dominación del hombre sobre la mujer desde una mirada eurocéntrica tratando de entablar una suerte de lucha de sexos, siguiendo el principio marxista de la lucha de clases. Sin embargo, su análisis solo hace referencia a la cuestión de la mujer sin denunciar otros aspectos como el miope imperialismo cultural europeo, o el dominio económico de los estados fuertes sobre los débiles, situaciones que repercutieron directamente en la situación de la mujer en todas las culturas, en todas las épocas, en todos los lugares. Eso no significa obviar el debate sobre la condición de la mujer en el mundo, sino que no se debe abordar la cuestión de la mujer basándose únicamente en el aspecto sexual dejando de lado otros muchos aspectos igual de relevantes como, por ejemplo, el derecho a la educación, al trabajo remunerado, a la vida de familia, a la maternidad, a la filiación, al desarrollo profesional, cultural, económico, etc.

En efecto, la discusión de la condición humana, tanto masculina como femenina, se debe desarrollar a partir del concepto de persona bumana desde su diversidad sexuada. Según la profesora Castilla, ontológicamente este concepto "aún hoy, no está suficientemente clarificado y divulgado.» ${ }^{21}$ Por eso, en la actualidad es imperativo discutir y comprender a la persona humana desde la perspectiva de la exclusión y la complementariedad de las categorías de persona bumana masculina y persona bumana femenina. Es decir, el concepto de complementariedad de los sexos se debe entender a través de la antropología metafísica que propone una mirada pragmática del concepto de hombre/persona humana masculina y mujer/persona humana femenina como partes distintas, pero equiparadas, de la raza humana. Este enfoque es el resultado de la reflexión filosófica de Julián Marías, quien la desarrolla para descubrir aquel nivel de realidad que él denomina «...la estructura empírica de la vida humana.»»

En primer lugar, el profesor Marías entabla la discusión definiendo el concepto de persona, y realiza un recuento histórico del término. Según lo indica el filósofo, "Persona" se deriva del griego prosopón

«Por supuesto, el sentido más interesante de esta voz griega, el que se ha tomado como fundamento o punto de partida de la noción de "persona», es aquel en que coincide con la voz latina: la máscara, por ejemplo la máscara trágica o cómica de los actores. De ahí se derivan 
las significaciones de «papel»o «carácter»o «personaje» y últimamente «persona». Es posible, aunque no seguro, que la significación de prósopon como máscara se deba a una influencia del latín persona; esta palabra es de etimología dudosa, probablemente etrusca.. ${ }^{23}$

Desde esta perspectiva, siempre al decir de Marías, el concepto clásico de persona que perduró hasta tiempos modernos lo acuñó Boecio. Para este filósofo de la Antigüedad Tardía, la persona era Rationalis naturae individua substantia" (substancia individual de naturaleza racional). En esta tradición, la persona se consideraba como el animal superior por excelencia de la creación; sin embargo, persistía en considerarlo como «una cosa con alguna mayor dignidad y excelencia que las demás. $\aleph^{24} \mathrm{La}$ escolástica medieval, y por ende los pensadores occidentales de las diversas épocas, se apoyó en esta concepción del hombre.

Apartándose de dicha línea escolástica tradicional, Marías propone un concepto de persona diferente: «Entendemos por persona una realidad que no es sólo real. Una persona 'dada' dejaría de serlo. El carácter programático, proyectivo, no es algo que meramente acontezca a la persona, sino que la constituye. La persona no «está ahí», nunca puede como tal estar ahí, sino que está viniendo. ${ }^{25}$ Persona, para el filósofo vallisoletano, incluye la realidad inmanente del individuo en la que se incluye su porvenir:

"Yo soy una persona, pero "el yo" no es la persona. "Yo" es el nombre que damos a esa condición programática y viniente. Cuando digo 'yo', me "preparo" o "dispongo" a ser. Para el hombre, ser es prepararse a ser, disponerse a ser, y por eso consiste en disposición y disponibilidad. ${ }^{26}$

Es decir, la persona se traza hacia el futuro desde su realidad presente, a lo que Marías llama la futurización del «yo»; en otras palabras, la persona se proyecta en un predicado que se conjuga en un presente y futuro continuo, trascendente que luego se torna en su historia. Así, la persona alcanza la plenitud de su dimensión humana ontológica a través de su "yo" en continuidad.

Ahora bien, la persona individualmente no desarrolla esa historia en el vacío, pues el individuo es parte de una comunidad de personas con quienes conlleva esta futurización del yo. Al tomar conciencia de sí mismo, de ese «yo» intrínseco, mayor es el conocimiento que debería adquirir como persona. Sin embargo, esa apertura trae consecuencias graves para ese «yo» proyectado. $\mathrm{Ma}$ rías aclara lo siguiente:

«Cuanto más sé quién soy, cuanto más poseo mi realidad programática y proyectiva, futuriza, irreal y viniente, cuanto más auténticamente soy 'yo' en el modo de la vida personal, menos sé qué va a ser de mí, más incierta es mi realidad futura, más abierta a la posibilidad, la invención, el azar y la innovación. Esta es la radical menesterosidad del hombre 
como persona, proyectado hacia adelante, de cara al futuro, yendo hacia lo otro y, sobre todo, hacia el otro; la persona necesita a la otra persona en la medida en que se le presenta como tal. $»^{27}$

De esto se deduce que la persona humana no puede proyectarse vectorialmente como individuo solitario, sino que necesita del concurso de sus semejantes para cumplir con el proyecto de esa «realidad programática y proyectiva, futuriza, irreal y viniente». Por lo tanto, el concurso del conjunto de otros «yo» es imprescindible para realizarnos en el «yo» que nos habíamos trazado.

Si la comunidad está conformada tal como la define Émile Durkheim, ya sea abierta o cerrada, entonces el individuo se ve enfrentado a diversas proyecciones que lo definirán a pesar de sí mismo, si es que no ha tomado conciencia de qué es él o ella como persona humana en su radicalidad sexuada. Por eso, si el principio de la persona sexuada no está correctamente definido en la sociedad moderna, la confusión y el conflicto aparecen indefectiblemente. Se puede, entonces, conjeturar que en nuestras sociedades actuales se advierta que el concepto de ser humano no toma en cuenta la condición sexuada de la humanidad, lo que ha llevado a que los conceptos se manipulen y se tergiversen de tal manera que ya no existe un significado claro de lo que es la persona humana.

Al suponer que el principio básico de "ser humano" es asexuado, tal como la filosofía tradicional lo define, ello concedería que la mujer también debería disfrutar de los mismos derechos y responsabilidades inherentes a su condición de participantes del colectivo humano. Pero, no se entendió así. ¿En qué momento se le negó su condición humana a la mitad de la población mundial? Blanca Castilla de Cortázar afirma que «Si se repasa la historia de la antropología, la mujer podría llamarse también "la gran desconocida"». ${ }^{28}$ Es decir, las disquisiciones filosóficas atendieron solo un aspecto de la cuestión humana obviando el carácter sexuado por ser considerado un accidente y no una realidad ontológica. Responder a este cuestionamiento, es decir explicar qué o quién es la mujer, rebasa el ámbito de este trabajo, aunque queda latente como línea de investigación para otros trabajos.

La denuncia sobre el silencio en cuanto al papel que la mujer jugó en la construcción de las culturas, tal como se menciona líneas arriba, vale para civilizaciones inscritas en diferentes partes del mundo, en temporalidad tanto diacrónica como sincrónica. Para efectos del presente trabajo, solo nos interesa centrarnos en la cultura occidental judeo-cristiana, que es en la que se inscribe la obra de Mercedes Cabello, aunque eso no signifique que algunos de los argumentos señalados no sean válidos para otras realidades culturales.

Pero, si el mundo pertenecía a los hombres tal como lo planteó Simone de Beauvoir, entonces, ¿cuál era la solución que se le ofrecía a la mujer? Según 
la filósofa francesa, las mujeres en busca de libertad se encuentran ante una disyuntiva: aceptar el statu quo, en el que los prejuicios sociales prevalecen, o dominar a la masculinidad en el ámbito público:

«...la sociedad codificada por los hombres decreta que la mujer es inferior y ella sólo puede abolir esa inferioridad destruyendo la superioridad viril. Se dedica a mutilar, a dominar al hombre; lo contradice: niega su verdad y sus valores. Mas con ello no hace otra cosa que defenderse; no han sido ni una esencia inmutable ni una elección culpable las que la han condenado a la inmanencia, a la inferioridad. Le han sido impuestas. Toda opresión crea un estado de guerra. Y este caso no es una excepción. $\aleph^{29}$

Es obvio, entonces, que la posición beauvoiriana se traduce en la «declaración de guerra» entre los sexos por el control del sistema. Es decir, era inevitable que los hombres y las mujeres caminasen en un trayecto de pertinaz colisión.

En tal sentido, Javier Marías propuso una revisión de las posiciones adoptadas tanto por hombres como mujeres para llegar a un lugar común:

«El hombre y la mujer, cuando se refieren a estos y en tanto en que no salen de su esfera, coinciden enteramente, porque no están hablando de realidades efectivamente constituidas en sus vidas, sino de objetos abstractos e irreales; pero tan pronto como entran en la esfera de la concreción, la realidad con la cual tienen que habérselas - y que es rigurosamente real-, está radicada en sus vidas respectivas, aparece en ellas, condicionadas por su estructura biográfica, inseparables de su punto de vista o perspectiva, del contexto efectivo en que cada una de ellas está trabada con las demás; y la razón, que es la aprehensión de esas realidades en su conexión, funciona de dos maneras diferentes pero no separables, ya que la peculiaridad de lo masculino y lo femenino es su recíproca referencia.. ${ }^{30}$

En otras palabras, mientras los paradigmas de hombre y mujer permanecieran tal como habían sido concebidos por el pensamiento occidental a lo largo de los siglos, las condiciones de la mujer seguirían igual. En tal sentido, lo que Marías señala es que la condición sexuada del ser humano no se tomó en cuenta en el plano abstracto porque se consideraba que el espíritu trascendía esa diferenciación; es decir, el sexo es un accidente y no una parte intrínseca de la esencia humana. Marías argumentó que se hacía indispensable revisar el concepto de "ser humano" como categoría filosófica para añadirle la dimensión sexual en la definición.

La profesora María del Carmen Ibañez Lascurain afirma lo siguiente sobre la condición masculina/femenina del ser humano: 
«La sexualidad es una dimensión de la persona que la abarca íntegramente por toda la vida; hombres y mujeres difieren no sólo físicamente, sino en todo su funcionamiento corporal, emocional e intelectual. Esto no implica la superioridad o inferioridad de ninguna; ambos son personas con una igual dignidad ontológica, con idénticos derechos y deberes para consigo mismos y para con los demás. Sin embargo, en su dimensión sexual, varón y mujer son profundamente distintos; son dos modos diversos de vivir y completar la visión del mundo.» ${ }^{31}$

Frente a esta diversidad es válido, entonces, que ambos sexos indaguen sobre su estatuto ontológico como individuos complementarios de la raza humana, y a partir de ello, buscar formas de convivencia que no se basen en la confrontación. Para ello se deben revisar y cuestionar aquellas posturas promovidas por grupos ideológicos que postulan la igualdad totalitaria entre hombres y mujeres trayendo como consecuencia la lucha por el poder sobre la sociedad.

Dicho lo anterior, lo que se requiere en ese sentido es buscar una vía en la que ambas partes de la humanidad trabajen en conjunto, entendiéndose como segmentos fundamentales de una unidad. Eso significa desarrollar el concepto de la UNIDUALIDAD RELACIONAL COMPLEMENTARIA de los sexos en la construcción de la cultura humana desde la verdad ontológica del individuo, tanto masculino como femenino. Una de las investigadoras de este campo es la Dra. Blanca Castilla, quien en 1996 publica Persona femenina, persona masculina, donde afirma lo siguiente:

«Distinguir entre persona masculina y persona femenina sugiere que la diferencia varón-mujer se encuentra en lo más íntimo del ser humano, en la persona, hasta llegar a configurar el propio "yo". Sin embargo [sic] esto resulta novedoso para la Antropología Metafísica realizada hasta ahora, que ha considerado a la persona como asexuada y se ha centrado en una consideración abstracta de la naturaleza humana, tratando siempre del "hombre" en general, sin considerar que en la realidad solamente existen varones o mujeres. ${ }^{32}$

Esta nueva forma de concebir a la persona humana desde la categoría sexual revoluciona el concepto mismo de la naturaleza humana. Ya no se puede hablar, entonces de una igualdad esencial entre varón y mujer porque intrínsecamente existen diferencias que los identifican como tales. Por supuesto, el concepto diferencial de esta nueva propuesta no es sinónimo de desigualdad, exclusión o discriminación, sino de complementariedad.

En este punto, es importante señalar que la noción de sexo presupone ir más allá del plano material o psicológico. Las categorías de "masculino" y "femenino" en la condición humana trascienden el horizonte del cuerpo y la mente para adentrarse en la ontología del ser humano. Castilla nos dice que: «Hay un salto 
cualitativo entre los animales y el ser humano que la condición sexuada puede tener en él un significado más profundo que el de colaborar en la transmisión de la vida, aun siendo ésta una dimensión importante y en cierto modo fundamental.» ${ }^{33} \mathrm{E} 1$ sexo, desde su función reproductiva, se limita a la conservación de las especies; pero, en el ser humano cala a tal punto que no solo es el impulso instintivo que nos lleva a la procreación de la especie, sino que marca a cada persona de manera total y definitiva. Por eso, reducir al sexo al ámbito puramente material, como un accidente más que distingue a una persona humana como parte de una u otra mitad de la raza humana, es reducir su capacidad de identificación al ámbito meramente material.

Sin embargo, ¿qué es persona humana? Según Castilla, « [1]a filosofía, reflexionando sobre el ser humano, descubrió, en un momento dado, que la naturaleza humana - es decir, la composición de alma y cuerpo- no era la estructura más profunda del hombre. Más allá de la naturaleza se encuentra la persona.» ${ }^{34}$ Según Castilla, santo Tomás de Aquino supo distinguir a la persona humana del resto de los seres de la naturaleza porque:

«...la diferencia radical entre las cosas y las personas se halla en el orden del ser; el mismo esse humano es radicalmente diferente del esse de las cosas del cosmos. La diferencia no está sola ni principalmente en la esencia sino en el orden trascendental. Él [Sto. Tomás de Aquino] supo ver y expresar mejor que ninguno la radicación de la persona en el esse..135

A la luz de estas reflexiones, no es arriesgado afirmar que la concepción de la persona humana debe enfocarse de manera distinta a la propuesta por las diversas tendencias posmodernistas. Es imposible dejar de lado la radicalidad de la persona humana, materia y espíritu, en la economía de la vida; dicha radicalidad es el factor que eleva tanto a la persona humana femenina como a la persona humana masculina por encima del resto de la creación.

Ahora bien, esto explica a la persona humana, pero no esclarece la diferencia entre persona humana femenina y persona humana masculina. Hasta bien entrado el siglo XX, la definición filosófica del hombre no distinguía lo masculino y lo femenino en el plano ontológico. No obstante, esa posición varió, y seguirá variando en la medida que se vayan dilucidando las diferencias sexuales no solo como accidentales, sino como ontológicas. Dicho lo anterior, esas diferencias, según Blanca Castilla, no necesariamente deben ser sinónimos de desigualdad. Ella define al hombre y a la mujer como iguales y diferentes:

«En realidad somos iguales y diferentes simultáneamente y en lo mismo. Somos iguales por ser personas; por participar de la misma naturaleza; ambos tenemos cuerpo y espíritu. $Y$ a la vez somos diferentes en cuanto al cuerpo, la psicología y al modo de ver las cosas... Sin embargo somos 
más iguales que distintos, pues la diferencia se calcula únicamente en un $3 \%$... Esa pequeña diferencia nos hace complementarios.» ${ }^{36}$

Por eso, tanto hombres como mujeres son partes de lo que se conoce como la raza humana, con igualdad de derechos y responsabilidades en cuanto a su condición ontológica. Pero, a la vez, somos diferentes por estar constituidos de manera distinta corporal y psicológicamente, lo que determina la forma en que hombres y mujeres enfrentan las circunstancias que los rodean, el modo de ver el mundo y enfrentar la vida. Justamente esa particularidad nos hace complementarios en la diferencia.

Para explicar esta "equi-diferencia", Blanca Castilla acuña el término unidualidad humana que lo define como «dos seres humanos que se hacen uno.» ${ }^{37}$ Este concepto, según la filósofa española, se contrapone al sentido de complementariedad entendido a través del modelo andrógino platónico: un individuo dividido en dos que se complementan aportando cada cual su parte para crear al «uno». ${ }^{38} \mathrm{Al}$ contrario del modelo platónico, en la unidualidad no es uno que se divide en dos, sino que son dos que se unen para crear la unidad. Castilla argumenta que justamente lo que hace falta es desarrollar una «antropología diferencial» para entender a cabalidad cómo se relacionan la persona humana femenina y la persona humana masculina a través de este nuevo enfoque de complementariedad. Son ya siglos de escrutinio y ponderación sobre la cuestión del hombre desde el punto de vista andrógino; ahora hace falta examinar los conceptos filosóficos de lo que significa ser mujer. Janne Haaland Matláry, según cita Castilla, afirma que "el "eslabón perdido" del feminismo es "una antropología capaz de explicar en qué y por qué las mujeres son diferentes a los hombres" $" 39$

Para Castilla, la diferencia entre hombre y mujer se explica a partir del sexo como constitutivo de la persona y no un accidente, como lo hemos venido argumentado en el presente trabajo:

«Si el sexo configura la persona misma, se podría decir que la apertura constitutiva que tiene cada persona tiene dos modalidades. Esa MODALIZACIÓN [...] ES RELACIONAL [...] En cuanto a la apertura, el varón se abre de un modo peculiar: hacia afuera. La mujer también se abre a los demás a su modo: hacia dentro, acogiendo.» ${ }^{40}$

Heidegger llama al acto de ser del hombre (en el sentido metafísico) ser-con, «un modo de nombrar el rasgo estructural que constituye al Dasein y que señala a los otros, al prójimo en el sentido del próximo más o menos conocido» ${ }^{41}$ Obviamente, esta es la explicación ontológica del concepto «hombre» -incluyendo a la mujer - que hasta ahora ha prevalecido, y seguirá prevaleciendo en cuanto concepto dentro de la historiografía filosófica. Sin embargo, lo que 
Castilla argumenta es profundizar dicho concepto para incluir el sexo como parte constitutiva del ser y no accidente, tal como la filosofía clásica lo estableció desde siglos atrás. Desde la perspectiva de la antropología diferencial que la Dra. Castilla propone, se debe tomar en cuenta el modo, o modalización relacional, en que los dos sexos se corresponden con «el próximo» de Heidegger. ${ }^{42}$

Esta apertura hacia el otro se entendería a partir de las preposiciones «en» $\mathrm{y}$ «desde». Convencionalmente, la preposición es una categoría gramatical invariable en la lengua española que une dos elementos oracionales denotando la relación que existe entre ellos. La preposición «en» une dos elementos denotando «en qué lugar, tiempo o modo se realiza lo expresado por el verbo a que se refiere.» ${ }^{43}$. Esta preposición se adjudicaría a la persona humana femenina en un ser-con-en, pues la relación de la mujer con el próximo heideggeriano es de acogida abarcadora. La preposición «desde», por su parte, «denota el punto, en tiempo o lugar, de que procede, se origina o ha de empezar a contarse una cosa, un hecho o una distancia.» ${ }^{44}$ Con ella se describiría la relación del hombre en ser-con-desde, ya que su modo de relacionarse es a partir de él hacia afuera. La Dra. Castilla lo resume de esta manera:

«La realidad humana sería, entonces, disyuntivamente o SER-DESDE o SER-EN. Ahí radicaría la principal diferencia entre varón y mujer, en ser dos tipos de personas distintas, que se abren entre sí de un modo respectivo diferente y complementario... La diferencia no rompe la igualdad. Sobre la base de la reciprocidad se trata de una UNIDUALIDAD RELACIONAL COMPLEMENTARIA.» ${ }^{45}$

Bajo esta lógica, como es obvio, la concepción del ser humano cambia radicalmente para incorporar la igualdad de condiciones entre hombre y mujer, pues desde este enfoque las diferencias serán ontológicas, no accidentales. Ello significa que hombres y mujeres son distintos constitutivamente mas no desiguales, hecho que refuta categóricamente aquellas propuestas en las que la sexualidad humana se toma como una construcción cultural. Simone de Beauvoir se preguntaba, con mucha razón, «¿qué es ser mujer?» Las respuestas para esclarecer esa cuestión han sido numerosas tentativas fallidas porque las premisas no eran las correctas. La originalidad de Beauvoir estriba en la pregunta misma y en su intento por responderla; su equivocación fue tratar de "igualar" la condición femenina a la condición masculina en su intento de darle acceso a los derechos que le correspondía a la mujer en su condición de persona humana.

A diferencia de la postura beauvoiriana, la tesis de la unidualidad relacional complementaria es un paso hacia la respuesta correcta de lo que significa ser mujer. En realidad, el concepto de persona humana se enriquece de manera radical porque, a través de ella, muchos de los dilemas que las mujeres afrontan actualmente se resolverían sin el enfrentamiento que las ideologías reduccionistas del 
siglo pasado consideraron ineludibles. Actos inherentes a la persona humana femenina como la maternidad, el instinto de protección de la progenie y el velar por el bienestar del núcleo familiar serían vistos como parte constitutiva de su condición humana y no como impedimentos para su realización como individuo integrante de la sociedad. Se podría afirmar que esta perspectiva de ver a la mujer revolucionaría a todas las culturas, pues tendría que dar un viro de $180^{\circ}$ en la forma en que se entiende el papel que la mujer juega en la construcción de la sociedad humana. Y, justamente esa es la posición que intuitivamente asumió Mercedes Cabello de Carbonera cien años antes en sus dos últimas obras: tanto Blanca Sol como El Conspirador se construyen como el binomio hombre/mujer que deberán responder a las necesidades para la construcción de una sociedad humana moderna y progresista.

\section{Resultados y discusión de los mismos}

En su afán moralizador y siguiendo su agenda positivista, Cabello desarrolla en sus dos últimas novelas, Blanca Sol y El Conspirador, el modelo de pareja que no se ajusta al ideal progresista, sino precisamente lo contrario. En efecto, en Blanca Sol Cabello construye a la protagonista con los defectos que la descalifican como madre, educadora y ciudadana de una nación liberal. Para la autora, el personaje de Blanca Sol carece de las virtudes que la acreditarían como el agente moralizador de las siguientes generaciones: ella es la antítesis de la mujer ilustrada. En suma, Blanca Sol representa la imagen no deseada de la persona humana femenina en la sociedad peruana de la época.

Luego de Blanca Sol, la autora publica El Conspirador, autobiografía de un hombre público en la que desarrolla la imagen del hombre político, el hombre público, cuyos vicios también lo desautorizan como ejemplo de estadista. Así vemos que en ambos personajes se construyen las representaciones negativas de la mujer y el hombre; son los anti-modelos que, según la autora, son prevalentes en la sociedad de la época. Es decir, y siempre desde la perspectiva de doña Mercedes, los personajes de Blanca Sol y Jorge Bello se construyen copiando los vicios tanto en hombres como en mujeres muy presentes en la sociedad limeña de la época. En ambas obras se manifiesta claramente la agenda de ingeniería social cabelliana cuyo fin era el de moralizar al país.

El análisis de las obras cabellianas siempre apuntan a la importancia que Cabello de Carbonera adjudica al concepto de mujer, desde lo que se conoce como el Culto a la Domesticidad ${ }^{46}$. De hecho, este concepto no se aplica únicamente a la obra cabelliana, sino que es la concepción de vida decimonónica prevalente a partir de la segunda mitad del siglo XIX ${ }^{47}$ Dentro de los relatos cabellianos, y siguiendo los parámetros del culto a la domesticidad, se advierte que la mujer está llamada a ejercer una gran influencia en la formación moral 
de las siguientes generaciones: es la madre quien se convierte en la educadora por excelencia, siempre y cuando se adhiera a los postulados cientificistas de las sociedades modernas, en el sentido durkheimiano. Así, ya sea la prosperidad como la ruina, dependen en gran medida del comportamiento de la mujer en su rol de madre y educadora. Por eso, el personaje femenino que se proyecta en el discurso cabelliano alude al público femenino en particular; ella es la madre de familia tanto en potencia como de facto, ella es la responsable de la educación de su descendencia. Las mujeres son las guías de las siguientes generaciones; ellas están destinadas a ser modelos de integridad moral ante sus hijos y ante la sociedad. El deber de la mujer, entonces, se construye como madre educadora fomentando los valores morales que ayudarán a sus hijos, y especialmente a sus hijas, a crecer en virtudes como el trabajo, la honradez, la frugalidad, la honestidad, etc. A ella se le adscribe el papel de transmisora de los valores morales, la piedad y la laboriosidad doméstica, asumiendo un rol de apoyo en el quehacer económico de los estados ${ }^{48}$.

Por supuesto y siempre desde el pensamiento cabelliano, el concepto complementario al de mujer es el de hombre, sujeto social que se ubica en el ámbito público. Así, la esfera de influencia del hombre está fuera del ámbito doméstico, aunque obviamente la influencia del ámbito privado se traducirá en las acciones que los hombres realizarán en la sociedad. Por lo tanto, si bien el sexo masculino es el llamado a la acción en el plano público, sus acciones reflejarán lo que adquirió en el plano doméstico. Obviamente, la conducta de los políticos, su quehacer en la esfera política, se fundamentará en los principios y valores que se adquieren en los hogares. Si la familia es la piedra angular sobre la que se basa el edificio social, ella deberá sustentarse, a su vez, en los principios y valores dignos de individuos virtuosos, de una nación civilizada y progresista; lo contrario traería desgracia a la sociedad entera.

Desde este punto de vista, se hace necesario, entonces, revisar el concepto de persona humana en el que se debe incluir la categoría del sexo no como un accidente de la condición humana, sino como parte inherentemente radical de la misma. Por eso, nosotros coincidimos con lo postulado por la filósofa Blanca Castilla quien define al hombre y a la mujer con el ser-desde o el ser-en -el Dasein heiddegeriano- ontológicamente DISYUNTIVO. Es decir, al definir qué es la condición humana, está deberá forzosamente incorporar la diferenciación sexual no como un accidente de la persona humana, sino como parte inherente a ella. Eso representaría que la nueva definición del concepto de condición humana forzosamente deberá tomar en cuenta la disyunción ontológica de hombre/mujer como las dos partes propias del concepto a precisar.

En realidad, esta nueva perspectiva transformaría el modo en que se percibe a la mujer todas las culturas. En efecto, desde tiempos inmemoriales, el papel de las mujeres ha sido relegado a un segundo plano, en el mejor de los casos; su 
aporte al avance de las comunidades nunca se le concedió la importancia que se merecía tomándolo solamente como accesorio. No obstante, la magnitud de su contribución, las mujeres aún están a la espera del reconocimiento en el desarrollo; es más, las sociedades contemporáneas deben recordar que el papel que la mujer jugó en la construcción sociedades verdaderamente humanas fue complementario y absolutamente necesario.

En resumen, consideramos que la Teoría de la Complementariedad ofrece una visión mucho más comprensiva y afín a la postura que la autora de Blanca Sol y El Conspirador presenta en sus dos obras. Es más, postulamos que esta propuesta se aplique a la producción de las escritoras finiseculares del siglo XIX para verificar hasta qué punto coinciden en sus textos, tanto literarios como pedagógicos o de reflexión, el modo en que se verifica la construcción de los personajes tanto masculinos como femeninos. Sostenemos que esta visión daría un saludable cambio a los análisis literarios del corpus decimonónico que hasta ahora se han limitado a las visiones marxistas, feministas o de estudios culturales.

A la luz del análisis realizado a través de la teoría de la Complementariedad, la novela El Conspirador no puede ni debe tomarse como un tratado político, una fotografía del momento, o como el retrato de algunas figuras políticas de la post-guerra, enfoque que algunos críticos literarios proponen. En realidad, el estudio que formulamos se aleja diametralmente de los análisis que se han realizado hasta la fecha. En efecto, en general la crítica literaria se ha centrado en el tema político de la historia, pero ha dejado de lado la figura del caudillo desde una perspectiva mucho más abarcadora de la propuesta; esa propuesta, desde la visión cabelliana, es la construcción del modelo de hombre cabal y honesto, con principios liberales y progresistas, que asuma su responsabilidad frente a su destino como líder político de la nación.

La vida de Jorge Bello no solo es una crítica a la actuación de algunos personajes políticos coetáneos: es el estudio sociológico del modelo de hombre público que el país requería urgentemente para salir del marasmo derrotista en el que se encontraba. Pero, más allá del contexto inmediato, Mercedes Cabello apeló no solo a las clases dirigentes de su momento, sino que reclama ese mismo compromiso para con la patria particularmente a las siguientes generaciones; es decir, ella proyecta su discurso hacia los jóvenes cuya posición en la sociedad les llevaría a dirigir el destino del país. Su obra se construye como un llamado a la reflexión, la ponderación, y la autocrítica en los dirigentes políticos, presentes y futuros. Todos ellos debían asumir graves responsabilidades para dirigir a la nación y, por lo tanto, su propósito debía ser rectificar su intención para servir al pueblo más que buscar el provecho propio. 
Esta es la visión que intuitivamente propuso Mercedes Cabello de Carbonera en sus dos últimas obras. Tanto Blanca Sol como El Conspirador se inspiran en la concepción del hombre y la mujer trabajando conjuntamente, desde sus propias esferas de influencia, aportando con sus cualidades intrínsecas en la construcción de una sociedad peruana moderna, basada en los modelos de las naciones progresistas y liberales del momento. Es decir, la pensadora peruana trabajó la categoría de mujer como la otra parte integrante de la raza humana, que ciertamente había sido relegada a un segundo plano por prejuicios ancestrales. Doña Mercedes Cabello de Carbonera comprendió la miopía social que había postergado a la mujer a un papel social secundario por no haber sido comprendida en toda su dimensión de persona humana, condición que ella juzgaba injusta en todo sentido; ese es el eje conceptual que vemos dramáticamente plasmado en sus dos últimas obras. Si se toma en cuenta el momento histórico en que Mercedes Cabello plantea esta tesis se puede concluir que su postura es realmente revolucionaria y hasta profética, de ahí su relevancia dentro de la literatura, la crítica literaria y el pensamiento nacional.

\section{Notas}

1 Sobre este punto debemos enfatizar que aún no se han realizado trabajos serios de crítica literaria de esta obra, es decir, análisis desde la perspectiva literaria, alejados de cualquier sesgo político; es una omisión de parte de la comunidad intelectual literaria que deja incógnitas en la historia de la literatura peruana.

2 Este concepto lo hemos tomado a partir de la teoría de la complementariedad desarrollado por Niels Bohr, según lo explica Ana Rioja en su artículo "La filosofía de la complementariedad y la descripción objetiva de la naturaleza" (Universidad Complutense).

3 Para una revisión de los artículos de opinión de la escritora moqueguana se recomienda el libro Mercedes Cabello de Carbonera. Artículos periodísticos y ensayos del Dr. Ismael Pinto Vargas.

4 Este concepto lo hemos tomado a partir de la teoría de la complementariedad desarrollado por Niels Bohr, según lo explica Ana Rioja en su artículo "La filosofía de la complementariedad y la descripción objetiva de la naturaleza" (Universidad Complutense).

5 Ana Rioja. (1992). "La filosofía de la complementariedad y la descripción objetiva de la naturaleza”. Revista de Filosofía. Año 3, N V. España-Madrid, p. 270.

6 Ibid., p. 271.

7 Ibid., p. 272.

8 Ibid., p. 279.

9 Oscar Navarro Rojas. "El surgimiento de la complementariedad: Niels Bohr y la conferencia de Como". Revista Filosofía de la Universidad de Costa Rica, XLVIII (123-124), 65-76, enero-agosto 2010, p. 75.

10 Wolfang Strobl. "E1 Principio de Complementariedad y su significación Científico-Filosófica”. Anuario filosófico, Vol. 1, No 1, 1968, págs. 183-203. 
11 Ibid., p. 201

12 Ibid., p. 201

13 Yolanda Cárdenas Gómez. Epistemología, Ontología y Complementariedad en Niels Bohr. Memoria para optar al grado de doctor. Universidad Complutense de Madrid, 2004, p. 4.

14 Ibid., p. 193.

15 Ibid, p. 207.

16 María del Carmen Ibañez Lascurain. "Varón y mujer: dos modos distintos de vivir y completar la visión del mundo". Revista Panamericana de Pedagogía: Saberes y quehaceres del Pedagogo. Universidad Panamericana, Número 4, 2003, pp. 95-96.

17 Blanca Castilla. Persona femenina. Persona Masculina. Instituto de Ciencias para la Familia de la Universidad de Navarra. Ediciones Rialp S. A., Madrid, España1: 1996, p. 21.

18 Ibid, p. 21.

19 Julián Marías. Antropologia Metafísica. La estructura empirica de la vida humana. Ediciones Revista de Occidente, S. A., Madrid, España: 1970, pp. 165-166.

20 Este concepto se debe interpretar en el sentido clásico del término, en el que el sintagma "hombre" hace referencia tanto a hombres como mujeres.

21 Blanca Castilla. Persona femenina..., p. 30.

22 Julián Marías. Antropologia Metafísica, p. 9.

23 Ibid, p. 42.

24 Ibid, p. 43.

25 Ibid, p. 45.

26 Ibid, p. 45

27 Ibid, p. 48

28 Blanca Castilla de Cortázar. ¿્Fue creado el varón antes que la mujer? Reflexiones en torno a la antropología de la Creación. Ediciones Rialp S. A., Madrid, España (2005), p. 13. En esta obra, la autora afirma a continuación: "Como consecuencia, la autopercepción del varón que se conoce a sí mismo frente a la mujer-frecuentemente se ha desfigurado y deformado, por la presión de exclusivistas esquemas androcéntricos y patriarcales" (p. 13). Aunque la cita no está directamente referida al papel de la mujer en la humanidad, que es el tema que se desea centrar, este argumento es muy válido para comprender el porqué del desinterés del aporte femenino a la construcción del mundo tal como se conoce hoy en día.

29 Ibid., p. 711.

30 Javier Marías. Antropología Metafísica, p. 205

31 María del Carmen Ibañez Lascurain, "Varón y mujer: dos modos distintos de vivir y completar la visión del mundo", p. 95.

32 Blanca Castilla, Persona femenina, persona masculina. Documentos del Instituto de Ciencias para la Familia N² 22. Universidad de Navarra. Navarra, España: 1996, p. 21.

33 Ibid., p. 24.

34 Ibid., 29. 
35 Ibid., 32.

36 Blanca Castilla de Cortázar. La complementariedad varón-mujer. Documentos del Instituto de Ciencias para la Familia. Navarra, España: Ediciones Rialp, 2004, p. 15.

37 Ibid., 16.

38 Ibid., 15.

39 Ibid., 16.

40 Ibid., p. 21

41 Consuelo González Cruz, «El ser-unos-con-otros en la ontología fundamental de Heidegger». Estudios 95, vol. VIII, invierno 2010, p. 223.

42 Castilla, La complementariedad..., pp. 21-22.

43http://www.rae.es/obras-academicas/diccionarios/diccionario-de-la-lengua-espanola/ http://lema.rae.es/drae/?val=en

44http://www.rae.es/obras-academicas/diccionarios/diccionario-de-la-lengua-espanola/ http://lema.rae.es/drae/?val=desde

45 Castilla, La complementariedad..., p. 23.

$46 \mathrm{El}$ culto a la domesticidad fue una corriente social en la que se propugnaba la separación de las esferas de influencia en públicas (empleo remunerado fuera del hogar/mundo masculino) y privadas (cuidado del hogar e hijos/mundo femenino).

$47 \mathrm{E}$ sentido de pater familias que manejamos es el heredado de la tradición española, que a su vez se deriva del uso romano, en la que el padre de familia tenía jurisdicción sobre su esposa y los hijos con ciertas restricciones, impuestas por los usos y costumbres. Así, por ejemplo, en muchos matrimonios, la mujer conservaba el control de su fortuna y las propiedades que traía al matrimonio, así como su nombre de soltera como símbolo de su status social. Esta noción social se desarrolla a partir de la Revolución Industrial de finales del siglo XVII. En esta época surge en Europa y en Norteamérica una clase media mayoritariamente constituida por pequeños propietarios, abogados, médicos, artesanos, empleados, obreros asalariados, etc. Entonces, la familia, que hasta ese momento había funcionado como unidad social y económica a la vez, cambia para convertirse en un espacio constituido mayoritariamente por mujeres y niños. El hombre abandona el hogar para realizar una labor remunerada fuera del ámbito doméstico. Así, mientras la mujer se retrae a la esfera privada del hogar, el hombre asume rol protagónico en el ámbito público. En la visión social del diecinueve, el hombre encarna los valores decimonónicos inherentes a tal ámbito, entre los que podría figurar, por ejemplo: "pater familias", "guardián", "proveedor", etc.

48 Los trabajos realizados por historiadores, antropólogos, sociólogos, psicoanalistas, entre otros especialistas respecto del culto a la domesticidad y la separación de las esferas sociales durante los siglos XIX y XX son abundantes, como, por ejemplo, el artículo de Nancy Chodorow "Family Structure and Feminine Personality" (Princeton University Press, 1994). En Latinoamérica, tenemos investigadores como Norma Fuller, Jeanine Anderson, Gabriela Arango y Cecilia Blondet, entre otras, cuyos estudios abren el panorama histórico y social de la posición de la mujer en la cultura popular de la región. 


\section{Referencias}

Cabello de Carbonera, M. (1893). La Religión de la Humanidad. Carta al Señor D. Juan Enrique Lagarrigue. Lima, Perú: Imp. De Torres Aguirre.

-. Blanca Sol (Novela Social). (1894). 4ta. Lima, Perú: Ed. Carlos Prince, Impresor y Librero - Editor.

-.El Conspirador (Autobiografía de un hombre público). Novela Político-Social. (1892). 2da. Imp. Lima, Perú: Imp.de "La Voce D’Italia".

-. El Conspirador (Autobiografía de un hombre público). Novela Politico-Social. (2001) Lima - Perú: Kavia Cobaya Editores.

Cárdenas Gómez, Y. (2004). Epistemología, Ontología y Complementariedad en Niels Bohr. Madrid, España: Memoria para optar el grado de Doctor. Universidad Complutense de Madrid (PDF, recuperado el 26/07/13).

Castilla, B. (1996). Persona Femenina. Persona Masculina. Instituto de Ciencias para la Familia. Madrid, España: Editorial Rialp S. A.

- ¿ ¿Fue creado el varón antes de la mujer? Reflexiones en torno a la antropología de la Creación. (2005). Madrid, España: Ediciones Rialp S. A.

Durkheim, E. (1998). La división del trabajo. Ciudad de México, México: Editorial Colofón.

Marías, J. Antropología Metafísica. La estructura empirica de la vida humana. (1970). Madrid, España: Ediciones Revista de Occidente S. A.

Navarro Rojas, O. (2010) "El surgimiento de la complementariedad: Niels Bohr y la conferencia de Como". Revista Filosofía, XLVIII (123-124), 65-76, enero-agosto.

Pinto Vargas, I. (2017). Mercedes Cabello de Carbonera. Artículos periodísticos y ensayos. Lima - Perú: Fondo Editorial del Congreso del Perú.

Rioja, A. (1992). "La filosofía de la complementariedad y la descripción objetiva de la naturaleza”. Revista de Filosofía. Año 3, N V. Madrid, España: 257-282.

Strobl, Wolfang. (1968). "El Principio de Complementariedad y su significación Científico-Filosófica”. Anuario filosófico, Vol. 1, № 1, 183-203. 